\title{
Societal costs and burden of otitis media in Portugal
}

This article was published in the following Dove Press journal:

Journal of Multidisciplinary Healthcare

31 March 20I I

Number of times this article has been viewed

\author{
Anouk Speets' \\ Judith Wolleswinkel' \\ Cristina Cardoso ${ }^{2}$ \\ 'Pallas health research and \\ consultancy, Rotterdam, \\ the Netherlands; \\ ${ }^{2}$ GlaxoSmithKline, Algés, Portugal
}

Correspondence: Anouk Speets Pallas health research and consultancy, PO Box 2I238, 300I AE Rotterdam, the Netherlands

Tel +3 I 0104474449

$\mathrm{Fax}+310104474450$

Email speets@pallas-healthresearch.com

\begin{abstract}
This study aimed to estimate the resource consumption and societal impact of otitis media (OM) in children younger than five years of age in Portugal. An Internet survey on generic childhood symptoms and diseases was administered to a sample of parents. This self-report survey had been previously implemented in other European countries. Medically confirmed OM was defined as symptoms of earache or "running ear" and/or a diagnosis of OM provided by a medical doctor. Direct medical, nonmedical, and indirect nonmedical costs were calculated for individual cases. Mean total costs per OM episode were estimated at $€ 334$. This corresponds to an estimated societal impact of 72 million $€ /$ year, of which $39 \%$ were indirect nonmedical costs. An epidemiological study should help to confirm the results of this study, and evaluate whether an intervention to reduce the occurrence and/or duration of OM may have an impact on societal costs and quality of life for affected families.
\end{abstract}

Keywords: otitis media, costs, societal burden, Portugal

\section{Introduction}

Otitis media is one of the most common childhood diseases, a leading cause for medical consultations, and the most frequent reason for prescribing antibiotics in children. ${ }^{1}$

The incidence of OM peaks at the age of 6-11 months. At the age of three years, $50 \%-85 \%$ of all children have suffered from at least one episode of OM. ${ }^{2}$ Recurrent OM (at least four episodes per year) is common, affecting up to $20 \%$ of children under one year of age; and up to $40 \%$ of older children eventually have six or more episodes in total. ${ }^{2}$ The worst symptoms usually dissipate within three (range 2-7) days. ${ }^{2}$ However, long-term consequences of OM can occur, and the most common cause of acquired hearing loss in childhood is OM with effusion. It has also been associated with delayed language development and behavioral problems. ${ }^{2,3}$

The societal impact of OM is potentially large because of its frequent occurrence in young children and the use of medical resources. Even when parents do not seek medical care for their child, they may still need to take days off work to care for their child and/or buy drugs, such as analgesics and antipyretics. In some countries, costs related to parental loss of productivity have been reported to represent $40 \%-60 \%$ of the total costs of OM, depending on country, age, and number of previous episodes. ${ }^{4,5}$

However, for most countries, solid data on the use of medical resources for OM are lacking, including the proportion of caregivers who do not seek medical care. In addition, limited data are available on the societal impact of OM, because data on loss of productivity and leisure time by parents are lacking in the scientific literature for common childhood diseases, including OM. Sometimes data from neighboring 
countries, validated by national experts, are used because of a lack of national data. ${ }^{6}$

It is important to have country-specific data on medical resource use and productivity loss, because differences in health care systems affect the proportion of parents seeking medical care for their child, the type of health service used, and the frequency of visits. In addition, countries differ in treatment guidelines, eg, those related to antibiotic use. Portugal does not have general regulations on antibiotic use in OM. The magnitude of indirect costs will depend on employment rate, average family income, the proportion of part-time workers among women and men, parental leave arrangements, loss of leisure time, and value attributed to unpaid jobs.

Without being able to establish the real picture, when it comes to cost and resource consumption, it is very difficult to assess and quantify familial economic effects. This also leads to severe limitations in our ability to evaluate the societal cost-effectiveness or cost-utility of an intervention in a given pathology. OM is a good example of this, being an infectious disease. Interventions, eg, vaccination or a campaign for rational use of antibiotics in the pediatric setting, should be compared with the preintervention situation in order to assess reliably their value to society.

We aimed to contribute to the knowledge of burden of disease, resource use, and societal costs of treating OM in Portugal. The objective of this study was to estimate medical resource use and the societal impact of OM in children younger than five years in Portugal, which has not been evaluated before.

\section{Methods}

The Internet survey used in this research was developed for a previous similar study in other European countries ${ }^{7}$ and, where necessary, adapted to reflect local realities (ie, questions on geographical distribution, income, local medicines, and consultation reimbursement system). Domains included sociodemographic data, characteristics of the illness (ie, symptoms, duration, and frequency), use of medical resources, loss of productivity by caregivers, and travel-related costs. When developing the loss of productivity questions, both the Productivity and Disease Questionnaire (PRODISQ) $^{8}$ and Health and Labor Questionnaire (HLQ) ${ }^{9}$ were evaluated and relevant items were included.

In March 2009, the questionnaire was administered to a sample of Portuguese parents with children younger than five years, who participated in the largest Internet access panel from an international market research agency,
Survey Sampling International, based in Rotterdam, the Netherlands. The respondents were selected based on their background characteristics. They received a standard invitation by email with a link to the Internet survey. The questionnaire was generic, such that respondents could fill out the questionnaire for all kinds of symptoms and diseases. All data, including a diagnosis received from a doctor and any antibiotic prescriptions were self-reported by the respondents. It was technically impossible to complete the questionnaire more than once. Exclusion criteria for this study were respondents without children, respondents without children aged younger than five years, most recent disease episode of the child being more than one year ago, or children who had not been ill.

\section{Case definition}

Respondents were asked to provide details of the most recent illness episode (within the last twelve months) suffered by their child. If parents had more than one child under the age of five years, they were asked to complete the questionnaire for the child that had most recently been ill. Doctor-diagnosed OM was defined as symptoms consistent with OM (at least earache and/or "running ear") warranting a clinic visit at which a diagnosis of $\mathrm{OM}$ had been received from a doctor. Cases were also classified as doctor-diagnosed OM if a diagnosis of OM was made by a doctor even if no symptoms of OM had been reported.

\section{Loss of productivity}

Loss of productivity included absence from a paid or unpaid job, as well as loss of productivity at work and/or leisure time. A paid job was defined as "paid employment" or "being self-employed". Data on work absenteeism per episode are presented for all caregivers combined, ie, the total hours of work lost by all caregivers as a result of the disease episode (mother, father, grandparent, and/or other caregiver). Absence from an unpaid job was defined as not being able to provide normal informal care to others, absence from any other voluntary work, and not being able to carry out activities around the house. ${ }^{10}$ Details were sought for the most recent disease episode in order to obtain reliable data on loss of productivity.

To investigate the loss of productivity for parents who went to work during the disease episode, parents were asked whether they felt less productive at work because of their child's illness, eg, because they were tired and could not concentrate properly. If this was the case, the parent was asked to provide an estimate of the extra hours they felt would 
have been needed to be as productive as when the child was not ill. This question has been shown to yield conservative results for loss of productivity at work. ${ }^{11}$ The results for loss of productivity at work are presented for parents combined, ie, the total time missed related to the episode of illness by both parents. One parent filled out the questionnaire for $\mathrm{him} /$ herself and the partner.

Loss of leisure time was defined as the amount of time during free weekdays or during weekends that the child's episode of illness consumed as a result of needing to consult a doctor or visit a pharmacy. Respondents were asked to report on loss of leisure time at the household level (meaning leisure time lost by all caregivers combined).

\section{Absence from kindergarten or daycare}

Respondents were asked whether their child attended any type of daycare institution and the duration of absenteeism during the episode of illness. Although this was not added to total costs, because these were transfer costs, absenteeism represents a loss of money for parents, because refunds or discounts are not usually given.

\section{Calculation of costs per episode of illness}

Costs were calculated from the societal perspective, including direct medical episode (clinic visits, hospitalization, prescriptions, and over-the-counter drugs), direct nonmedical costs (travel), and indirect nonmedical costs (loss of productivity and leisure time). Costs per episode of illness were calculated for individual cases based on the type and frequency of health services used and the amount of hours of productivity lost multiplied by the unit costs. The unit costs for medical consultations and hospitalizations are unit costs from the Portuguese National Health Service.

The costs of medication were based on the costs paid by the respondents themselves. They also included information on whether part of the total cost was reimbursed by the National Health Service or paid by their health insurer. The individual costs were used to calculate means, medians, standard deviations (SDs), and ranges for all costs combined for a episode of OM. A specification of the unit costs for the year 2009 is shown in Table 1. The costs of public transport and medication were reported directly by the respondents.

Table I Unit costs associated with otitis media in Portugal

\begin{tabular}{|c|c|c|}
\hline & Costs $(€)$ & Comments/reference \\
\hline \multicolumn{3}{|l|}{ Direct medical costs } \\
\hline General practitioner visit* & 31 & Ministry of Health, 2009 \\
\hline Home visit by general practitioner* & 42 & Ministry of Health, 2009 \\
\hline Outpatient pediatrician visit* & 31 & Ministry of Health, 2009 \\
\hline Outpatient ear-nose-throat specialist visit* & 31 & Ministry of Health, 2009 \\
\hline Outpatient consult other medical doctor* & 31 or 85 or 100 & Depending on doctor, Ministry of Health, 2009 \\
\hline Telephone consultation medical doctor* & 25 & Ministry of Health, 2009 \\
\hline Emergency department visit* & 147 & Ministry of Health, 2009 \\
\hline Hospital stay (I day with overnight stay)* & 78.02 & Ministry of Health, 2009 \\
\hline Accompanying person hospital stay* & 112.50 & Ministry of Health, 2009 \\
\hline Antibiotics treatment & & $\begin{array}{l}\text { As filled out by the respondents or when missing } 9.55 \text {; } \\
\text { Ministry of Health, } 2009\end{array}$ \\
\hline Other prescribed drugs & & As filled out by the respondents \\
\hline OTC drugs & & As filled out by the respondents \\
\hline \multicolumn{3}{|l|}{ Direct nonmedical costs } \\
\hline Cost of I km travelled by car & 0.40 & Public Administration Legislation, 2009 \\
\hline Public transportation costs & & As filled out by the respondents \\
\hline Taxi costs & & As filled out by the respondents \\
\hline \multicolumn{3}{|l|}{ Indirect costs } \\
\hline \multicolumn{3}{|l|}{ Absence paid job: average hourly wage paid job } \\
\hline Mother & 5.59 & Ministry of Work and Social Security, 2009 \\
\hline Father & 7.41 & Ministry of Work and Social Security, 2009 \\
\hline Grandparent & 6.50 & Ministry of Work and Social Security, 2009 \\
\hline \multicolumn{3}{|l|}{ Hours productivity lost: average hourly wage paid job } \\
\hline Mother & 5.59 & Ministry of Work and Social Security, 2009 \\
\hline Father & 7.41 & Ministry of Work and Social Security, 2009 \\
\hline Absence unpaid job: average hourly wage unpaid job & 3.00 & Ministry of Work and Social Security, 2009 \\
\hline Average hourly cost of leisure time loss & 3.00 & Ministry of Work and Social Security, 2009 \\
\hline
\end{tabular}

Note: *Unit costs for National Health Service. 


\section{Estimation of costs in Portugal}

There are no data on the incidence of OM in Portugal. Data have been reported by Garcés-Sánchez et al, but these were derived from a Spanish study. ${ }^{12}$ Spain can be used as a reference country for Portugal, because of the similarities in terms of distribution of sociodemographic data, the health care system in place, and patterns of antibiotic use. The data reported by Garcés-Sánchez et al show an annual $\mathrm{OM}$ incidence of 40 per 100 children younger than five years and, if extrapolated to Portuguese children, represents a total of 214,648 OM cases. We multiplied the number of episodes by the cost per episode calculated from data collected in our study.

\section{Statistical analysis}

Data on medical resource use and indirect cost indicators (eg, hours of work lost) were described in terms of absolute numbers, means, medians, SDs, and ranges. The data were screened for incorrect values, and these were treated as missing values. For loss of productivity, incorrect values were defined as reports of hours of work lost per episode exceeding twelve hours per caregiver per sick day per child. Data were analyzed using SPSS for Windows (v 16.0; SPSS Inc, Chicago, IL).

\section{Results}

\section{Study population and OM episodes}

In total, 5423 persons embarked on completing the questionnaire. Of these, 612 persons did not complete the Internet survey and 3042 persons were screened out because they did not meet the inclusion criteria, ie, had no children $(n=2306)$, had no children younger than five years of age $(n=414)$, most recent disease episode occurred more than one year ago $(n=63)$, or children had not yet been ill $(\mathrm{n}=259)$. This resulted in 1769 respondents reporting on 1769 childhood disease episodes. The respondents in this survey were comparable with the general Portuguese population with respect to gender and gross household income in this age group. However, the level of education of the respondents was higher than the education level of the general Portuguese population. Further details of the respondents are given in Table 2.

Among the 1769 disease episodes, 291 (16\%) had symptoms of OM (ie, earache or running ear), of which 203 episodes (12\%) could be classified as doctor-diagnosed OM. The mean age of the children with doctor-diagnosed OM was $2.5 \pm 1.5$ years, and $46 \%$ were girls (Table 2 ), reflecting the
Table 2 Characteristics of the respondents and children

\begin{tabular}{|c|c|c|}
\hline & n (\%) & n (\%) \\
\hline & $\begin{array}{l}\text { All respondents } \\
(\mathrm{n}=1769)\end{array}$ & $\begin{array}{l}\text { MD-OM } \\
(n=203)\end{array}$ \\
\hline \multicolumn{3}{|l|}{ Respondents } \\
\hline Gender, female & $893(50.5)$ & $98(48.3)$ \\
\hline $\begin{array}{l}\text { Mean age } \pm S D \text { in years } \\
\text { (range) }\end{array}$ & $\begin{array}{l}30.7 \pm 5.2 \\
(16.0-65.0)\end{array}$ & $\begin{array}{l}30.7 \pm 4.8 \\
(18.0-49.0)\end{array}$ \\
\hline \multicolumn{3}{|l|}{ Level of education* } \\
\hline Basic & $220(12.4)$ & $34(16.7)$ \\
\hline Secondary & $668(37.8)$ & $72(35.5)$ \\
\hline Higher & $768(43.4)$ & $79(38.9)$ \\
\hline Postgraduate & $113(6.4)$ & $18(8.9)$ \\
\hline \multicolumn{3}{|l|}{ Regions } \\
\hline Viana do Castelo & $20(I . I)$ & $5(2.5)$ \\
\hline Vila Real & $21(1.2)$ & I $(0.5)$ \\
\hline Braga & $107(6.0)$ & II (5.4) \\
\hline Bragança & II (0.6) & 0 \\
\hline Porto & $308(17.4)$ & $28(13.8)$ \\
\hline Viseu & $45(2.5)$ & $9(4.4)$ \\
\hline Aveiro & $123(7.0)$ & $15(7.4)$ \\
\hline Guarda & $17(1.0)$ & $2(1.0)$ \\
\hline Coimbra & $97(5.5)$ & $10(4.9)$ \\
\hline Castelo Branco & $34(1.9)$ & $\mathrm{I}(0.5)$ \\
\hline Leiria & $87(4.9)$ & II (5.4) \\
\hline Santarém & $64(3.6)$ & $6(3.0)$ \\
\hline Portalegre & $25(1.4)$ & $4(2.0)$ \\
\hline Lisboa & $451(25.5)$ & $60(29.6)$ \\
\hline Setúbal & $201(11.4)$ & $21(10.3)$ \\
\hline Beja & $17(1.0)$ & $2(1.0)$ \\
\hline Évora & $20(I . I)$ & $3(1.5)$ \\
\hline Faro & $73(4.1)$ & $9(4.4)$ \\
\hline \multicolumn{3}{|l|}{ da Madeira } \\
\hline \multicolumn{3}{|l|}{ dos Açores } \\
\hline $\begin{array}{l}\text { Paid job; mean number } \\
\text { of hours per week** } \pm \text { SD } \\
\text { (range) }\end{array}$ & $\begin{array}{l}I, 44 \mathrm{I}(8 \mathrm{I} .5) ; \\
37.8 \pm 10.4 \text { hours } \\
\text { (range 3.0-100.0) }\end{array}$ & $\begin{array}{l}175(86.2) ; \\
38.2 \pm 12.3 \text { hours } \\
\text { (range } 5.0-100.0 \text { ) }\end{array}$ \\
\hline Gross yearly household & $20,000-29,999$ & $20,000-29,999$ \\
\hline income (median) & Euros & Euros \\
\hline $\begin{array}{l}\text { Mean number of children } \\
\text { ( }<5 \text { years) per respondent }\end{array}$ & I.I children & I.I children \\
\hline \multicolumn{3}{|l|}{ Children/episodes } \\
\hline Gender; girls & $768(43.4)$ & $94(46.3)$ \\
\hline $\begin{array}{l}\text { Mean age } \pm S D \text { in years } \\
\text { (range) }\end{array}$ & $\begin{array}{l}2.5 \pm 1.5 \\
\text { (range } 0.1-4.9 \text { ) }\end{array}$ & $\begin{array}{l}2.5 \pm 1.5 \\
\text { (range } 0.1-4.9 \text { ) }\end{array}$ \\
\hline \multicolumn{3}{|l|}{ Age distribution } \\
\hline 0 year & $38 \mid(2 \mid .5)$ & $47(23.2)$ \\
\hline $0-6$ months & $156(8.8)$ & $24(11.8)$ \\
\hline $6-12$ months & $225(12.7)$ & $23(11.3)$ \\
\hline I year & $364(20.6)$ & $31(15.3)$ \\
\hline 2 years & $369(20.9)$ & $51(25.1)$ \\
\hline 3 years & $264(14.9)$ & $25(12.3)$ \\
\hline 4 years & $391(22.1)$ & $49(24.1)$ \\
\hline
\end{tabular}

Notes: *Basic: 4th grade; 9th grade; Secondary: I2th grade; Higher: Degree (licenciatura4 to 6 years); Postgraduate studies: Masters, PhD.

Abbreviations: SD, standard deviation; MD-OM, doctor-diagnosed otitis media. 
normal age and gender trend found in the literature. There were seven cases with symptoms consistent with OM that had not been diagnosed by a doctor.

The mean duration of a doctor-diagnosed OM episode was $6.1 \pm 7.5$ days. Episodes with symptoms of OM for which no clinic visit had been made were shorter ( $4.3 \pm 3.1$ days). According to the definition of recurrent OM (at least four episodes in the past twelve months), $9 \%$ of the children had recurrent OM. ${ }^{13}$ The Internet survey did not have the ability to find out about any underlying conditions that could explain increased risk in certain individuals, eg, cleft palate or immunological deficiencies.

\section{Health care use}

Of all cases with symptoms of OM (ie, earache or "running ear") in the sample, 341 (98\%) did see a doctor. This is higher than for childhood diseases in general, because in the total sample of 1769 cases with all childhood disease episodes, $88 \%$ did visit a doctor. Table 3 shows the distribution of medical resources used for episodes of doctor-diagnosed OM $(n=203)$. A pediatrician was visited most frequently (46\%). Three children (1.5\%) with doctor-diagnosed OM were admitted to hospital for one day without an overnight

Table 3 Use of medical resources for episodes of doctor-diagnosed otitis media

\begin{tabular}{|c|c|}
\hline & $n=203$ \\
\hline \multirow{2}{*}{\multicolumn{2}{|c|}{$\begin{array}{l}\text { Doctor* consultation, \%, mean visits per } \\
\text { episode (range) }\end{array}$}} \\
\hline & \\
\hline GP & $25.1,2.1(I-6)$ \\
\hline GP home visit & $3.9,1.9(I-5)$ \\
\hline Pediatrician & 46.3, $2.1(1-9)$ \\
\hline Emergency department visit & $34.0,1.8(1-10)$ \\
\hline Ear-nose-throat specialist & $8.4,2.7(I-6)$ \\
\hline Other medical doctor & $2.0,1.2(I-2)$ \\
\hline Telephone doctor consultation & $3.9,3.5(1-12)$ \\
\hline \multicolumn{2}{|c|}{ Hospital admission, \% (mean duration, days) } \\
\hline Without overnight stay & I.5 (I.0) \\
\hline Including overnight stay & $4.4(3.9)$ \\
\hline \multicolumn{2}{|l|}{ Drug prescription, n (\%) } \\
\hline Drugs prescribed & $196(96.6)$ \\
\hline Antibiotics & $186(91.6)$ \\
\hline In children aged 0 year & $43(91.5)$ \\
\hline In children aged I year & $28(90.3)$ \\
\hline In children aged 2 years & $47(92.2)$ \\
\hline In children aged 3 years & $22(88.0)$ \\
\hline In children aged 4 years & $46(93.9)$ \\
\hline Other drugs & $21(10.3)$ \\
\hline No drugs prescribed & $7(3.4)$ \\
\hline Nonprescription drugs, n (\%) & $100(49.3)$ \\
\hline
\end{tabular}

Note: *More than one option could be filled out. Abbreviations: SD, standard deviation; GP, general practitioner. stay, and nine children (4.4\%) were admitted for a mean duration of 3.9 days. Not only were the number of prescribed antibiotics high (92\%), but also nonprescribed drugs were frequently used in cases with doctor-diagnosed OM (49\%).

\section{Loss of productivity}

In most cases, the mother (approximately 52\%) and/or grandparents (about 47\%) cared for the sick child during the day. Loss of productivity and leisure time is summarized in Table 4. For $27 \%$ of the doctor-diagnosed OM episodes, caregivers had to take time off from a paid job (mean absence $19.8 \pm 23.0$ hours). In cases of unpaid work, the proportion of doctor-diagnosed OM episodes for which caregivers lost work days was $14 \%$ (mean absence $13.8 \pm 12.7$ hours).

Table 4 Productivity loss and travel-related costs for episodes with doctor-diagnosed otitis media

\begin{tabular}{|c|c|}
\hline & $n=203$ \\
\hline \multicolumn{2}{|l|}{ Paid work } \\
\hline $\begin{array}{l}\text { Children for whom caregivers* had to } \\
\text { stay home, } \mathrm{n}(\%)\end{array}$ & $55(27.1)$ \\
\hline Mean \pm SD absence, hours (range) ${ }^{\dagger}$ & $\begin{array}{l}19.8 \pm 23.0 \text { hours } \\
(1.0-160.0)\end{array}$ \\
\hline Median absence in hours & 16.0 \\
\hline \multicolumn{2}{|l|}{ Unpaid work } \\
\hline $\begin{array}{l}\text { Children for whom caregivers had to } \\
\text { stay home, } \mathrm{n}(\%)\end{array}$ & $28(13.8)$ \\
\hline Mean \pm SD absence, hours (range) ${ }^{\dagger}$ & $\begin{array}{l}13.8 \pm 12.7 \text { hours } \\
(1.0-51.0)\end{array}$ \\
\hline Median absence, hours & 8.0 \\
\hline \multicolumn{2}{|l|}{ Loss of work productivity } \\
\hline Parents reporting loss of productivity, n (\%) & $|3|(64.5)$ \\
\hline $\begin{array}{l}\text { Mean } \pm \text { SD loss of productivity loss, hours } \\
\text { (range) }\end{array}$ & $\begin{array}{l}21.0 \pm 25.3 \text { hours } \\
(0-144.0)\end{array}$ \\
\hline Median productivity loss, hours & 14.0 \\
\hline \multicolumn{2}{|l|}{ Loss of leisure time } \\
\hline Parents reporting loss of leisure time, $\mathrm{n}(\%)$ & I45 (7I.4) \\
\hline Mean \pm SD loss of leisure time, hours (range) ${ }^{*, t}$ & $\begin{array}{l}3.5 \pm 8.5 \\
(0.1-100.0)\end{array}$ \\
\hline Median loss of leisure time, hours & 2.0 \\
\hline \multicolumn{2}{|l|}{ Travel-related costs } \\
\hline \multicolumn{2}{|l|}{ Car km } \\
\hline Parents reporting car km, n (\%) & $158(77.8)$ \\
\hline Mean car km $\pm S D(\text { range })^{*, \dagger}$ & $\begin{array}{l}15.4 \pm 18.9 \\
(0.5-150)\end{array}$ \\
\hline Median car km & 10.0 \\
\hline \multicolumn{2}{|l|}{ Public transportation costs } \\
\hline $\begin{array}{l}\text { Parents reporting public transportation costs, } \\
\mathrm{n}(\%)\end{array}$ & $4(2.0)$ \\
\hline \multicolumn{2}{|l|}{ Taxi costs } \\
\hline Parents reporting taxi costs, n (\%) & $\mathrm{I}(0.5)$ \\
\hline
\end{tabular}

Notes: *Mother, father, grandparent, other; ${ }^{\dagger}$ population = caregivers who reported productivity loss; ${ }^{\ddagger}$ parents.

Abbreviation: SD, standard deviation. 
Loss of productivity at work was reported by $65 \%$ of parents having a child with doctor-diagnosed OM.

Besides loss of work hours for parents or other caregivers, childhood OM may also decrease leisure time, eg, time consumed by a clinic visit or collecting drugs from a pharmacy. In cases of doctor-diagnosed OM, 71\% of parents reported loss of leisure time (mean loss $3.5 \pm 8.5$ hours per disease episode).

\section{Absence from kindergarten or daycare}

In total, $88 \%$ (178 children) of the 203 children with OM episodes attended daycare and were absent for a mean of 2.6 days. Apart from the loss of income for parents, it is very useful to ascertain daycare attendance, because close and continued contact with children of the same age group can result in exchange of bacterial flora and eventually lead to drug-resistant strains. ${ }^{14}$

\section{Direct and indirect costs of OM}

The mean costs per disease episode of doctor-diagnosed OM were estimated to be $€ 334$ (95\% confidence interval [CI]: €286-382), of which 59.6\% were direct medical costs, $1.5 \%$ were direct nonmedical costs, and $38.9 \%$ were indirect nonmedical costs (Table 5). Forty-four percent of the direct medical costs were attributable to emergency room visits, followed by $15 \%$ for pediatrician visits, and $10 \%$ for antibiotic prescriptions. Loss of productivity at work accounted for $66 \%$ of indirect costs and absence from a paid job accounted for $24 \%$.

\section{Incidence and prevalence}

If we assume that there are 214,648 new episodes of doctordiagnosed OM each year in Portugal among children younger than five years, this will result in 552,246 clinic visits associated with OM in this age group. Applying these assumptions, the estimated economic burden to Portuguese society is approximately $€ 72$ (95\% CI: €61-82) million, of which $39 \%$ of expenditure is attributable to indirect nonmedical costs (Table 5).

\section{Discussion}

Internet surveys are a novel and comparatively recent method of investigation. Therefore, it is important to assess properly their suitability and the reliability of results to establish the robustness of each element within a study.

\section{Selection bias}

Selection bias is apparent for all types of surveys and is not related only to Internet panels. This Internet survey was
Table 5 Direct medical, direct nonmedical, indirect and total costs of doctor-diagnosed otitis media episodes and economic burden of otitis media in Portugal

\begin{tabular}{|c|c|c|}
\hline & $\begin{array}{l}\text { MD-OM } \\
\text { Internet } \\
\text { survey }(n=203)\end{array}$ & $\begin{array}{l}\text { MD-OM } \\
\text { Portugal } \\
(n=2 \mid 4,648)\end{array}$ \\
\hline \multicolumn{3}{|l|}{ Direct medical costs $(€)$} \\
\hline Total costs & 40,443 & \\
\hline $\begin{array}{l}\text { Mean costs per episode } \\
(95 \% \mathrm{Cl}) \pm \mathrm{SD}\end{array}$ & $199(164-234) \pm 253$ & \\
\hline Median costs per episode & 137 & \\
\hline Range costs per episode & $20-2227$ & \\
\hline $\begin{array}{l}\text { Total costs to society } \\
(95 \% \mathrm{Cl})\end{array}$ & & $\begin{array}{l}42,714,952 \\
(35,202,272- \\
50,227,632)\end{array}$ \\
\hline \multicolumn{3}{|c|}{ Direct nonmedical costs $(€)$} \\
\hline Total costs & 1010 & \\
\hline $\begin{array}{l}\text { Mean costs per episode } \\
(95 \% \mathrm{Cl}) \pm \mathrm{SD}\end{array}$ & $5(4-6) \pm 7$ & \\
\hline Median costs per episode & 2 & \\
\hline Range costs per episode & $0-60$ & \\
\hline $\begin{array}{l}\text { Total costs to society } \\
(95 \% \mathrm{Cl})\end{array}$ & & $\begin{array}{l}1,073,240 \\
(858,592- \\
I, 287,888)\end{array}$ \\
\hline \multicolumn{3}{|l|}{ Indirect costs (€) } \\
\hline Total costs & 26,355 & \\
\hline $\begin{array}{l}\text { Mean costs per episode } \\
(95 \% \mathrm{Cl}) \pm \mathrm{SD}\end{array}$ & $130(101-159) \pm 209$ & \\
\hline Median costs per episode & 69 & \\
\hline Range costs per episode & $0-1519$ & \\
\hline Total costs to society & & $27,904,240$ \\
\hline$(95 \% \mathrm{Cl})$ & & $\begin{array}{l}(21,679,448- \\
34,129,032)\end{array}$ \\
\hline \multicolumn{3}{|l|}{ Total costs $(€)$} \\
\hline Total costs & 67,808 & \\
\hline $\begin{array}{l}\text { Mean costs per episode } \\
(95 \% \mathrm{Cl}) \pm \mathrm{SD}\end{array}$ & $334(286-382) \pm 348$ & \\
\hline Median costs per episode & 226 & \\
\hline Range costs per episode & $25-2369$ & \\
\hline $\begin{array}{l}\text { Total costs to society } \\
(95 \% \mathrm{Cl})\end{array}$ & & $\begin{array}{l}71,692,432 \\
(61,389,328- \\
81,995,536)\end{array}$ \\
\hline
\end{tabular}

Abbreviations: $\mathrm{Cl}$, confidence interval; MD-OM, doctor-diagnosed otitis media; $\mathrm{SD}$, standard deviation.

generic for all kinds of symptoms and childhood diseases. To prevent selection bias for OM, we did not explicitly specify that our main research subject was OM. However, it is still possible that parents with children who got sick frequently were more willing to fill out the questionnaire. If these children had OM, this may have resulted in an overestimation of the true incidence and related costs of OM.

\section{Internet panel and representativeness of sample}

An Internet access panel was used to gather data on health care expenditure and loss of productivity. An important 
criticism in this regard is that a population with Internet access may not be a representative sample of the general population. Therefore, an Internet survey is only appropriate if the study topic is suitable for an Internet population to minimize bias and increase the external validity of the results. ${ }^{15}$ For this survey, we could target the population for which the topic, ie, medical resource use and loss of productivity associated with childhood illness, was relevant, being targeted to parents with children younger than five years. The majority of these parents are likely to be in their late 20 s or $30 \mathrm{~s}$, which nowadays is a very Internet-literate age group in most countries. In Portugal, 77\% of men aged 16-24 years and $41 \%$ of men aged $25-54$ years use the Internet at least once a week and, for women, these percentages were $77 \%$ and $33 \%$, respectively. ${ }^{16}$

The respondents in this survey were largely comparable with the general population in the same age group for gender and household income. This is important, because an association has been confirmed between income and use of health care services. Van Doorslaer et al examined the factors driving inequalities in use of general practitioner and specialist services in twelve European Union member states. ${ }^{17,18}$ In most countries, no evidence of inequity was found in the distribution of general practitioner visits across income groups. However, after controlling for differences in need, people with higher incomes are more likely to see a specialist and also more frequently. Pro-rich inequity is especially large in Portugal, Spain, and Italy. In Portugal, much of the pro-rich distribution appears to be related to the high proportion paid for out-of-pocket expenses (or through private insurance) for private consultations and limited access to specialist services in poorer regions. ${ }^{17,18}$

One may also argue that, facing similar costs per episode, families on lower incomes will have to make an extra effort to treat their child, because several costs are similar across the different socioeconomic classes. To avoid potential bias, we used a conservative approach to estimate costs. All private medical consultations and private emergency rooms visits were rated at Portuguese National Health Service prices, although their costs are considerably higher and in many cases are rated as out-of-pocket expenses. Our questionnaire did not explore the reasons behind parents' decision to use private health care facilities.

\section{Self-reported data}

All data, including those on symptoms and diagnosis, were self-reported or proxy-reported (ie, where individuals could answer questions for those who are unable to answer on their own behalf, eg, persons who filled out questions on behalf of their partner). A self-reported diagnosis by a doctor was not validated with medical files. Even when OM diagnoses are validated in medical files, there may still be some uncertainty about the diagnosis of OM, because of the lack of universally accepted diagnostic criteria. ${ }^{19}$ Studies have shown that parents are capable of recognizing OM. Vernacchio et al have demonstrated that parents' reporting of their child's OM episode occurring in the previous month was likely to be accurate, with a positive predictive value of $85 \%$ and a negative predictive value of $99 \% .{ }^{20}$ Another study has shown that sociodemographic characteristics of the proxy-respondent, such as age, education, and income, are not related to reported clinic visits or hospitalizations in the previous year. ${ }^{21}$

\section{Recall}

The recall period could also influence the accuracy of reported medical resource utilization and loss of productivity. With respect to data on medical resource use, general practitioner visits tend to be underreported more often than use of hospital-based health care services, eg, emergency department visits and hospitalizations. ${ }^{22}$ The results of this Internet survey are largely based (in $81 \%$ of cases) on a recall duration of just two months. Severens et al investigated the accuracy of a retrospective, self-administered questionnaire about sick leave by comparing self-reported data with company-registered absence data. ${ }^{23}$ For a recall period of six months, $87 \%$ of the self-reported results matched the registry data, reducing to $51 \%$ for a recall period of twelve months. Because most of our cases (81\%) occurred in the previous two months, we anticipate a high level of accuracy from our measurement of productivity and loss of leisure time.

In addition, the respondent was asked to report loss of productivity for other caregivers. This could lead to an underestimate of work absenteeism when the respondent could not provide this information. However, only a minority of respondents reported not knowing whether other caregivers lost hours from their paid job (2\%) or unpaid job (5\%). On average, $76 \%$ of work absenteeism and loss of productivity was applicable to the respondent himself or herself, and $24 \%$ was applicable to another caregiver.

\section{Recurrent otitis media}

Recurrent OM is defined as at least three separate and well documented episodes within six months or at least four episodes within twelve months, ${ }^{13}$ with one of the episodes occurring recently. In this survey, parents were asked to 
report on the most recent disease episode. This could have created a bias toward recurrent episodes of OM. Children with multiple OM episodes are more likely to have an OM episode as their most recent disease episode compared with children who had just one OM episode in the previous year. Information on the prevalence of recurrent $\mathrm{OM}$ is scarce in the medical literature. It is generally agreed that $10 \%-20 \%$ of children under one year of age will have recurrent OM, and that $40 \%$ of children will have more than six episodes during childhood. ${ }^{2}$ The finding of a $9 \%$ rate for recurrent $\mathrm{OM}$ in Portugal is at the low end of this range.

It is possible that families with more children and more episodes of OM may experience more pronounced effects from additional episodes. For example, after multiple OM episodes, it can be more difficult to find a person to take care of the child, resulting in more work absenteeism. This study did not take into account the effects of multiple OM episodes, which may have resulted in an underestimation of the cost estimate per OM episode. Furthermore, this particular group merits a specific cost study, because of the need for further interventions to minimize hearing loss problems, including myringotomy, tympanostomy tube insertion, speech and language evaluation and therapy, management of permanent sequelae, and overall decreased contribution to the community arising from not reaching their individual potential, ${ }^{14}$ which was outside the scope of this study. Brouwer et al reported a considerable negative impact of recurrent OM on children's quality of life which was proportionate to disease severity, and affecting the general wellbeing of children and their families. ${ }^{24}$

\section{Loss of productivity}

Work days lost from a paid or unpaid job largely depends on the participation of parents, particularly women with young children in the work force. In some countries, the employment rate is low, but when women do work, they work fulltime; in other countries, employment rates are high, but the large majority of women with children work part-time. In Portugal, $81 \%$ of women work fulltime, 13\% have a substantial part-time job (20-34 hours/week), and only $6 \%$ have a marginal part-time job. The percentage of women with marginal part-time jobs is among the lowest in Europe. ${ }^{25}$ However, the percentage of disease episodes for which caregivers had to stay home from a paid job was $27 \%$ for doctor-diagnosed OM. This could be explained by the high percentage (46\%) of grandparents who took care of their grandchildren with doctor-diagnosed OM.
Another important figure when calculating indirect costs is the mean wage of caregivers. Caregivers were mainly women, whose mean wage is considerably lower than that for men. In Portugal, women currently earn on average $€ 895$ and men earn on average $€ 1,186$ per month. ${ }^{26}$ It should be further investigated whether one of the reasons for women being the primary caregiver could be the fact that women's absenteeism has less impact on the total family income.

\section{Cost calculation}

The human capital approach was used for the cost calculation of loss of productivity, ${ }^{10}$ in which we did not correct for compensation of work hours lost by colleagues or parents themselves. However, we did ask about these compensatory mechanisms. Compensation for absence from work occurred for about $25 \%$ of all OM-associated work hours lost (about $50 \%$ of respondents reported compensation for about $50 \%$ of the hours) and for about $5 \%$ of all hours of lost productivity at work associated with a child's OM. If we correct for compensation of lost hours, the indirect costs would be reduced from $€ 130$ (95\% CI: €101-159) to $€ 116$ (95\% CI: €91-141) per episode of doctor-diagnosed OM.

\section{Antibiotic consumption}

The respondents reported antibiotic prescriptions for $92 \%$ of episodes of OM in children younger than five years. There is a lack of studies on antibiotic prescriptions in children with OM in Portugal, other than one on bacterial prevalence of OM reported in 1999, in which the authors mention heavy antibiotic use. Heavy antibiotic use may explain their finding of a high resistance profile, aggravated by kindergarten attendance and circulation of the most common pathogens being found to be resistant strains of Streptococcus pneumoniae and Haemophilus influenzae. ${ }^{27}$ Cars et al reported data on outpatient antibiotic sales (irrespective of the illness for which they were prescribed) in 1997 for 15 countries in the European Union. ${ }^{28}$ They showed that the daily defined dose of antibiotics per 1000 people varied more than four-fold between European countries. France (36.5), Spain (32.4), and Portugal (28.8) had the highest sales, whereas the Netherlands (8.9), Denmark (11.3), and Germany (13.6) had the lowest sales. This large variation is unlikely to be caused by differences in frequency of bacterial infections. Muller et al reported outpatient antibiotic use by approximately 24 per 1000 inhabitants per day in Portugal in 2005. ${ }^{29}$ Because OM is one of the most common indications for antibiotics in many Western countries, ${ }^{29}$ this 
could be an indication that antibiotic usage in children with OM is high in Portugal.

High antibiotic usage is also reported for non-European countries. For example, an Australian study of the economic cost of OM concluded that antibiotic prescribing rates remained high, despite clear evidence of a limited benefit from antibiotics in most $\mathrm{OM}$ cases and concerns about bacterial resistance. General practitioners prescribed antibiotics for acute OM for 82 of every 100 cases of OM managed during the period 2000-2007. Antibiotics prescribed by general practitioners for OM in children aged 0-14 years comprised $10 \%$ of all prescriptions (antibiotics and other drugs) prescribed by general practitioners for children in that age group. ${ }^{30}$

This leads us to the very important issue of lack of consensus about the management of $\mathrm{OM}$ in general, including in Portugal. A Finnish study in 2000 reported a wide variation in approaches to treatment. Broader spectrum antibiotics were used, with almost no serious complications (eg, mastoiditis, meningitis, brain abscess), but many more cases of recurrent OM and increased use of surgery (adenoidectomy and/or tympanostomy tube insertion) were reported. ${ }^{31}$

The same pattern is reported in another paper ${ }^{32}$ comparing strategies for OM management. Countries with a more conservative policy towards antibiotic use seem to be more liberal in their indications for surgery. Northern European countries use fewer antibiotics but more surgery. On the other hand, Southern European countries favor antibiotic use. The same pattern has been reported for the US. The authors considered their data to indicate a modest benefit from both antibiotics and surgery for children with OM. ${ }^{32}$

At a leading pediatric hospital in Coimbra (in the central region of Portugal), a team of pediatricians retrospectively evaluated their antibiotic prescriptions in the emergency room for two days per month selected at random during 2008. They concluded that, in 2863 children, OM was the major reason for antibiotic prescription, representing $24.5 \%$ of all prescriptions (oral antibiotics were prescribed in 404 children). Although the results represented a decrease compared with a similar study conducted in 2005 , the authors considered it as an opportunity to decrease even further their antibiotic prescriptions on this setting, and to adopt a "wait and see" strategy in a greater number of cases. ${ }^{33}$

This may also link to the growing awareness of the role of bacterial biofilms in OM and the lack of or decreased antibiotic activity on bacteria organized in a network. ${ }^{34}$

The "wait and see" approach advocates treatment of pain and delayed antibiotic prescribing, with active vigilance to ascertain whether the disease episode will be selflimiting. ${ }^{35}$ However, the "wait and see" approach does not seem to be justified in children younger than two years of age, unless very tight vigilance can be implemented, due to the small caliber of the Eustachian tube, along with its horizontal orientation in this age group, resulting in impaired clearance and ventilation of the middle ear. To these anatomical characteristics we must add an immature immune system and long-lasting dysfunction of the Eustachian tube (after an OM episode) prone to recurrence. Also, the lack of evidence for the value of ventilation tube insertion and improvement of Eustachian tube dysfunction has been mentioned in the literature. ${ }^{31,36}$

\section{Conclusion}

This Internet survey has added important data to existing knowledge regarding the use of medical resources and loss of productivity associated with OM in Portugal. Until now, these data have been largely lacking. The medical and economic burden of OM to society is considerable, and an intervention that would reduce the occurrence or duration of OM could have a major societal impact. Furthermore, these data could offer an opportunity to undertake a cost-effectiveness study comparing preventive and curative interventions for OM, and to ascertain whether the former would be the preferable approach.

\section{Acknowledgments}

Editorial assistance was provided by the authors Anouk Speets of Pallas health research and consultancy and Cristina Cardoso. The authors thank Elhem Sbaa (KeyrusBiopharma for GlaxoSmithKline Biologicals) for medical writing help and manuscript coordination services during the preparation of this manuscript. The authors acknowledge Hans Tamminga and Sofia Andre for their input on the manuscript and their valuable comments.

\section{Disclosure}

This study was sponsored by GlaxoSmithKline Biologicals. Otherwise, the authors report no conflicts of interest in this work.

\section{References}

1. Rovers MM. The burden of otitis media. Vaccine. 2008;Suppl 7: G2-G4.

2. Rovers MM, Schilder AG, Zielhuis GA, Rosenfeld RM. Otitis media. Lancet. 2004;363(9407):465-473.

3. Roberts JE, Rosenfeld RM, Zeisel SA. Otitis media and speech and language: A meta-analysis of prospective studies. Pediatrics. 2004;113 (3 Pt 1):e238-e248. 
4. Capra AM, Lieu TA, Black SB, Shinefield HR, Martin KE, Klein JO. Costs of otitis media in a managed care population. Pediatr Infect Dis J. 2000;19(4):354-355.

5. Niemelä M, Uhari M, Möttönen M, Pokka T. Costs arising from otitis media. Acta Paediatr. 1999;88(5):553-556.

6. Bergman A, Hjelmgren J, Ortqvist A, et al. Cost-effectiveness analysis of a universal vaccination programme with the 7-valent pneumococcal conjugate vaccine (PCV-7) in Sweden. Scand J Infect Dis. 2008;40(9): 721-729.

7. Wolleswinkel-van den Bosch JH, Stolk EA, Francois M, Gasparini R, Brosa $\mathrm{M}$. The health care burden and societal impact of acute otitis media in seven European countries: Results of an Internet survey. Vaccine. 2010;28 Suppl:G39-G52.

8. Koopmanschap MA. PRODISQ: A modular questionnaire on productivity and disease for economic evaluation studies. Expert Rev Pharmacoecon Outcomes Res. 2005;5(1):23-28.

9. Van Roijen L, Essink-Bot ML, Koopmanschap MA, Bonsel G, Rutten FF. Labor and health status in economic evaluation of health care. The Health and Labor Questionnaire. Int J Technol Assess Health Care. 1996;12(3):405-415.

10. Oostenbrink J, Koopmanschap MA, Rutten FF. Guide to cost research Methods and standard costs prices for economic evaluations in health care. Amstelveen, The Netherlands: Health Care Insurance Board; 2004. Dutch.

11. Brouwer WBF, Koopmanschap MA, Rutten FF. Productivity losses without absence: Measurement validation and empirical evidence. Health Policy. 1999;48(1):13-27.

12. Garcés-Sanchez M, Díez-Domingo J, Alvarez de Labiada T, et al. Epidemiology and burden of acute otitis media in Valencia (Spain). An Pediatr (Barc). 2004;60(2):125-132.

13. Hendley JO. Clinical practice: Otitis media. NEngl JMed. 2002;347(15): 1169-1174.

14. Klein JO. The burden of otitis media. Vaccine. 2000;19 Suppl 1: S2-S8.

15. Eysenbach G, Wyatt J. Using the Internet for surveys and health research. $J$ Med Internet Res. 2002;4(2):E13.

16. Smihily M. Internet usage in 2007. Households and individuals. Eurostat Data in Focus. 2007;23.

17. Van Doorslaer E, Koolman X, Jones AM. Explaining income-related inequalities in doctor utilisation in Europe. Health Econ. 2004;13(7): 629-647.

18. Van Doorslaer E, Masseria C, Koolman X; OECD Health Equity Research Group. Inequalities in access to medical care by income in developed countries. CMAJ. 2006;174(2):177-183.

19. Gunasekera H, Morris PS, McIntyre P, Craig JC. Management of children with otitis media: A summary of evidence from recent systematic reviews. J Paediatr Child Health. 2009;45(10):554-562.

20. Vernacchio L, Vezina RM, Ozonoff A, Mitchell AA. Validity of parental reporting of recent episodes of acute otitis media: A Slone Center Office-Based Research (SCOR) Network study. J Am Board Fam Med. 2007;20(2):160-163.
21. Rajmil L, Fernandez E, Gispert R, et al. Influence of proxy respondents in children's health interview surveys. J Epidemiol Community Health. 1999;53(1):38-42.

22. Petrou S, Murray L, Cooper P, Davidson LL. The accuracy of self-reported healthcare resource utilization in health economic studies. Int J Technol Assess Health Care. 2002;18(3):705-710.

23. Severens JL, Mulder J, Laheij RJF, Verbeek AL. Precision and accuracy in measuring absence from work as a basis for calculating productivity costs in The Netherlands. Soc Sci Med. 2000;51(2):243-249.

24. Brouwer CN, Rovers MM, Maillé AR, et al. The impact of recurrent acute otitis media on the quality of life of children and their caregivers. Clin Otolaryngol. 2005;30(3):258-265.

25. European Foundation for the Improvement of Living and Working Conditions. Part-time work in Europe. 2007. Available at: http://www. eurofound.europa.eu/ewco/reports/TN0403TR01/TN0403TR01.pdf. Accessed February 22, 2011.

26. Statistics Bulletin- Cabinet for Strategy and Planning, Ministry of Work and Social Security; December 2008. In Portuguese.

27. Monteiro L, Acosta L, Calado V. Contribution for the study of bacterial prevalence in children's Acute Otitis Media in Portugal. Rev Port ORL, 1999;37(3):193-200. In Portuguese.

28. Cars O, Molstad S, Melander A. Variation in antibiotic use in the European Union. Lancet. 2001;357(9271):1851-1853.

29. Muller A, Coenen S, Monnet DL, Goossens H; ESAC Project Group. European Surveillance of Antimicrobial Consumption (ESAC): Outpatient antibiotic use in Europe, 1998-2005. Euro Surveill. 2007; 12(10): E071011.1.

30. Taylor PS, Faeth I, Marks MK, et al. Cost of treating otitis media in Australia. Expert Rev Pharmacoecon Outcomes Res. 2009;9(2): 133-141.

31. Schilder AG, Lok W, Rovers MM. International perspectives on management of acute otitis media: A qualitative review. Int J Pediatr Otorhinolaryngol. 2004;68(1):29-36.

32. Joki-Erkkilä VP, Pukander J, Laippala P. Alteration of clinical picture and treatment of pediatric acute otitis media over the past two decades. Int J Pediatr Otorhinolaryngol. 2000;55(3):197-201.

33. Vaz Silva P, Mação P, Rodrigues R, Januário L. Evaluation of antibiotic prescription at an emergency room (pediatric). Abstract presented at 13th Week of Intern Physicians from CHC, EPE, 2009. In Portuguese.

34. Vergison A. Microbiology of otitis media: A moving target. Vaccine. 2008;26 Suppl 7:G5-G10.

35. Williamson I. The rocky road to rational prescribing. Vaccine. 2008;26 Suppl 7:G11-G15.

36. Corbeel L. What is new in otitis media? Eur J Pediatr. 2007;166(6): $511-519$
Journal of Multidisciplinary Healthcare

\section{Publish your work in this journal}

The Journal of Multidisciplinary Healthcare is an international, peerreviewed open-access journal that aims to represent and publish research in healthcare areas delivered by practitioners of different disciplines. This includes studies and reviews conducted by multidisciplinary teams as well as research which evaluates the results or conduct of such teams or

\section{Dovepress}

healthcare processes in general. The journal covers a wide range of areas and welcomes submission from practitioners at all levels, from all over the world. The manuscript management system is completely online and includes a very quick and fair peer-review system. Visit http://www.dovepress.com/testimonials.php to read real quotes from published authors. 